\title{
Comparative study of sperms motility analysis with CASA by using leja and microscope slide
}

\author{
Dian Ratnawati*1) and Muchamad Luthfi ${ }^{1)}$ \\ 1) Beef Cattle Research Institute Jl. Pahlawan Grati, Bebekan Lor, Ranu Klindungan, Kec. \\ Grati, Pasuruan, Jawa Timur, Indonesia, 67184
}

Submitted: 26 May 2019, Accepted: 18 May 2020

\begin{abstract}
The aim of this study was to compare the assessment of spermatozoa motility by using leja and microscope slide (MS). Fresh semen of four Ongole crossbred (PO) bulls were collected by using an artificial vagina. The semen with $70 \%$ sperms motility was diluted into into $30 \mathrm{million} / \mathrm{ml}$ concentration and assessed for its motility by using CASA (SCA 5.2 Microptic). The measured parameters in this study were sperms motility, progressive sperm motility, curve linear velocity (VCL), straight linear velocity (VSL), average pathway velocity (VAP), linearity (LIN), straightness (STR), wobble (WOB), hyperactivity (H), lateral head amplitude (ALH) and beat cross frequency (BCF). The data were analyzed by using independent simple t-test (IBM SPSS statistics 24). The results showed a hyperactive spermatozoa when analyzed by using leja was at $7.3 \%$, higher than assessed with Microscope slide $(2.8 \%)$. Meanwhile, other motility parameters (motility, progressive motility, VCL, VSL, VAP, LIN, STR, WOB, ALH and BCF) did not show any difference. Microscope slides can be used as a means of supporting sperms motility assesment by using CASA and more efficient.
\end{abstract}

Keywords: ledja; microscope slide; sperms motility; CASA

\footnotetext{
*Corresponding Author: dian_sapo@yahoo.co.id
} 


\section{INTRODUCTION}

The spermatozoa motility is a semen quality parameter that is often used as a benchmark for fertility status in bulls. Some other literatures state that in addition to spermatozoa motility, there are other parameters that are equally important in identifying the fertility of bulls, namely the morphology of spermatozoa (Arifiantini, Purwantara, Riyadhi, 2012; Barth and Oko, 1989). Sperms motility is an important factor that indicates the progressive movement of the spermatozoa when moving in the female reproductive tract to reach the oocyte and initiate fertilization.

Assessment of spermatozoa motility can be done visually or by using Computer Assisted Sperm Analysis (CASA). The advantages of using CASA is that the assessment would be fast, objective, repeatable, independent and can identify spermatozoa movements thoroughly and specifically (Susilawati, 2011; Rurangwa et al., 2004). In the CASA motility assessment, there are several influencing factors, which include the used sample, analyst competencies, type of CASA and the used settings. The sample temperature in the chamber, limited spermatozoa size and spermatozoa concentration greatly influenced to the results of spermatozoa motility analysis as well (Rurangwa et al., 2004). Sperm motility was assessed in a preheated slide or chamber and investigated on the warmer stage at $37^{\circ} \mathrm{C}$ (Vested et al., 2011).

Another study stated that sperm was analyzed in prewarmed leja at $39^{\circ} \mathrm{C}$ (Broekhuijse et al., 2011). Pipeting procedure and mixing before assessment also affect the spermatozoa motility. The experience and expertise of analysts in using CASA also has an important role in determining the results of the analysis. Whereas the type of CASA influences the assessment because each type has a standard sperm trajectory and a method of calculating the motility of spermatozoa. Algorithms, types and specifications of cameras used for shooting in each type of CASA are different so that it affects the results of the analysis.

One of many factors that influence to the motility assessment by using CASA is type of chamber. There are several types of chambers that can be used to analyze spermatozoa i.e. makler chamber, zander spermometer, minitube chamber, leica, leja, goldcyto etc (Massanyi et al., 2008; Peng et al., 2017). Basically, leja and microscope slide (which is covered with a glass cover) have the same work system, which is capillary forces. These two chambers easier to be found than the others. The price of microscope slide (MS) is cheaper than leja. The aim of this study was to compare the assessment of spermatozoa motility by using leja and microscope slide (MS).

\section{MATERIALS AND METHODS Material and Time of Research}

The materials used in this study were 4 Ongole crossbred (PO) bulls aged 4-6 years old. The duration of the study was 2 months (December 2017-January 2018). The research location was in Beef Cattle Research Institute

\section{Semen Collection}

Semen were collected twice a week. The sperm motility of used semen in this study were more than $70 \%$. Semen collection was done 10 times with each ejaculation was replicated for 2 times. Semen collection was done by using an artificial vagina. The collected semen was diluted with CEP-2 extender until reached $30 \mathrm{million} / \mathrm{ml}$ concentration. Semen dilution was calculated as follow:

$\begin{array}{ll}\mathrm{V} 1 \mathrm{M} 1 & =\mathrm{V} 2 \mathrm{M} 2 . \\ \mathrm{V} 1 & : \text { Fresh semen volume }(\mathrm{ml}) \\ \mathrm{V} 2 & \begin{array}{l}\text { : Total volume of semen and } \\ \text { extender }(\mathrm{ml})\end{array} \\ \mathrm{M} 1 \quad & \begin{array}{l}: \text { Fresh semen concentration } \\ (\text { million } / \mathrm{ml})\end{array} \\ \mathrm{M} 2 \quad & \begin{array}{l}\text { : Standard chilled semen } \\ \text { concentration }(100 \mathrm{million} / \mathrm{ml})\end{array} \\ & \begin{array}{l}\text { Specifications for Leja and } \\ \text { microscope slide in this study were: }\end{array}\end{array}$


1. Leja chamber (2 chamber slide) 20 microns, produced by Netherland. Rectangular shape with 2 chambers, size of chamber depth is $20 \mu$ with chamber volume capacity $\mu 1$.
2. $\quad$ Microscope slide (MS) $25.4 \mathrm{~mm} \times \mathbf{7 6 . 2}$ $\mathrm{mm}$, Chinese production. Rectangular shape, its use was covered using cover glass.
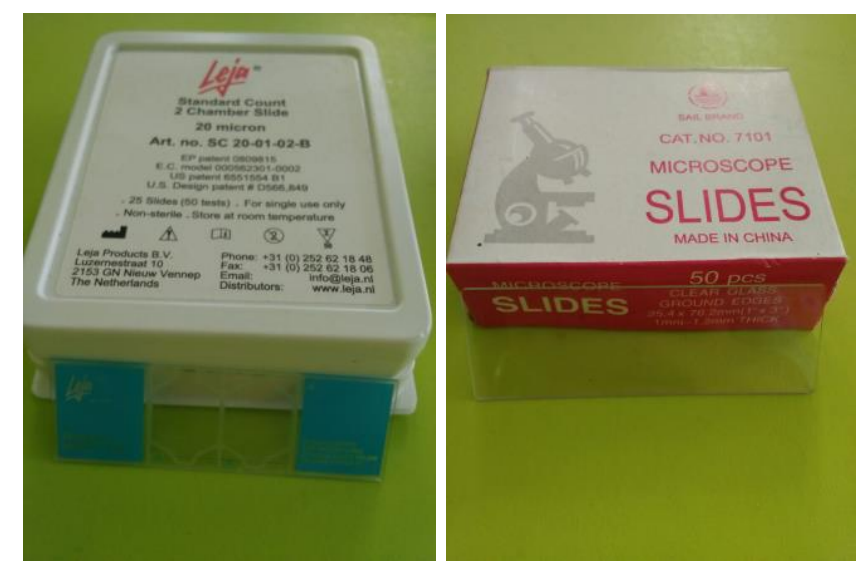

Figure 1. Leja 2 chamber 20 micron (left) dan Slide microscope (right)

\section{CASA Assessment}

Semen has been diluted, taken as much as 3-4 $\mu \mathrm{l}$ and placed in ledja and microscope slide which has been conditioned to $37{ }^{\circ} \mathrm{C}$. The type of CASA used is Sperm Class Analyzer (SCA) 5.2 Microptics, Spanish. The CASA settings were: $\mathrm{pH} 1$ contrast phase, $10 \mathrm{x} 10$ magnification and green filter on the reflector mirror. The light intensity was adjusted to the standards and printed on the monitor screen. The pictures were taken in 5 fields of view and the results were presented in the form of Microsoft Excel.

\section{Data Parameters and Analysis}

The measured parameters were sperm motility, progressive motility, static cells, VCL, VSL, VAP, LIN, STR, WOB, hyperactivity, ALH and BCF. The data were analysed by using IBM SPSS statistics 24 with independent t-test between two groups (Leja and microscope slide).

\section{RESULTS AND DISCUSSION}

The results of spermatozoa motility assessment between chamber types are listed in Table 1.

Table 1. Progressive Motility and Motility Spermatozoa of Ongole crossbred.

\begin{tabular}{lccc}
\hline \multirow{2}{*}{ Parameter } & \multicolumn{2}{c}{ Treatment } & \multirow{2}{*}{ Significance } \\
\cline { 2 - 3 } & Leja & Microscope Slide & \\
\hline Motility (\%) & $84.6 \pm 10.2$ & $87.2 \pm 7.0$ & $0.102(\mathrm{P}>0.05)$ \\
Progressive Motility (\%) & $50.6 \pm 14.5$ & $56.8 \pm 17.4$ & $0.195(\mathrm{P}>0.05)$ \\
Static cell (\%) & $15.4 \pm 10.2$ & $12.9 \pm 7.0$ & $0.102(\mathrm{P}>0.05)$ \\
\hline
\end{tabular}

Table 1. showed that there was no significant difference in the motility and progressive motility of spermatozoa by using Leja and microscope slide. These results are in accordance with the results of Massanyi et al. (2008) that the chamber microscope slide and standard $20 \mu \mathrm{L}$ chamber have no significant differences, except for DCL and DAP parameters. The motility and progressive motility of spermatozoa by using leja were $84.6 \mu \mathrm{m} / \mathrm{s}$ and $50.6 \mu \mathrm{m} / \mathrm{s}$; while using MS as a chamber is $87.2 \mu \mathrm{m} / \mathrm{s}$ and $56.8 \mu \mathrm{m} / \mathrm{s}$.

Motility value showed the percentage of moving spermatozoa at a speed of $>5 \mu \mathrm{m}$ / s. Meanwhile, the progressive motility of 
spermatozoa is the percentage of spermatozoa that move at a speed of $>40 \mu \mathrm{m}$ / s. Massanyi et al. (2008) stated that there are several factors that influence to the assessment of motility by using different chambers, including: age of bulls, sample collection (collection site), and dilution. During observation, the components in the diluent consisted of biological material (albumin and egg yolk) which caused a deposit. The mixing factor or mixing process which was not perfectly homogeneous suspension caused a less distributed spermatozoa. The position of sampling affected to the resulting assessment. Massanyi et al. (2008) stated that differences in the results of spermatozoa analysis with different chamber types produced different results. The difference in results is due to differences in chamber depth and adhesive properties of the different chamber surfaces.

Another study conducted by Contri et al. (2010) stated that the difference in chamber type between the Leja and Mackler chamber showed significant differences in the spermatozoa motility and movement. The Mackler chamber is a round shape with a volume chamber of $10 \mu \mathrm{L}$ and a depth of $10 \mu \mathrm{m}$. Leja chamber has a square shape with volume chamber $2 \mu \mathrm{L}$ and $20 \mu \mathrm{L}$ depth. The use of Leja chamber resulted higher static cell values and lower progressive motility than the Makler chamber. There is a Segre-Silberberg effect that can affected to the distribution of particles in suspension and liquid dynamics, so that it has an effect on the assessment produced (Gloria et al., 2013). Another factor that influences the spermatozoa motility is the speed of filling the sample in the chamber. It took 1-2 minutes to fill the chamber. In this study it has been followed according to the procedure. The longer time for filling chamber and analysis, there will be decreased sperm velocity.

Gaczarzewicz (2015) stated that the results of motility analysis of spermatozoa by using different chamber types produce different data. This is more due to the differences in the procedure for loading samples and the depth of the chamber. A higher chamber depth $(20 \mu \mathrm{L})$ provided the opportunity for the spermatozoa to move more freely and have higher energy to moving. The resulting pattern of movement is the high speed of spermatzoa (VCL, VSL and VAP), the pattern of head and tail movements of high spermatozoa (ALH and BCF), but not progressive (low STR and LIN). High VCL and ALH values and low STR are characteristic of hyperactive spermatozoa. The previous study reported that the differences types of chambers for CASA analysis resulted different results in various species (Gaczarzewicz, 2015; Krause, 1995; Rurangwa et al., 2004). This was probably one type of chamber fitted to one species resulting in almost similar to the actual movement of spermatozoa. Lenz et al. (2011) concluded that to control the quality of semen evaluation is to use one type of chamber in certain species within each analysis
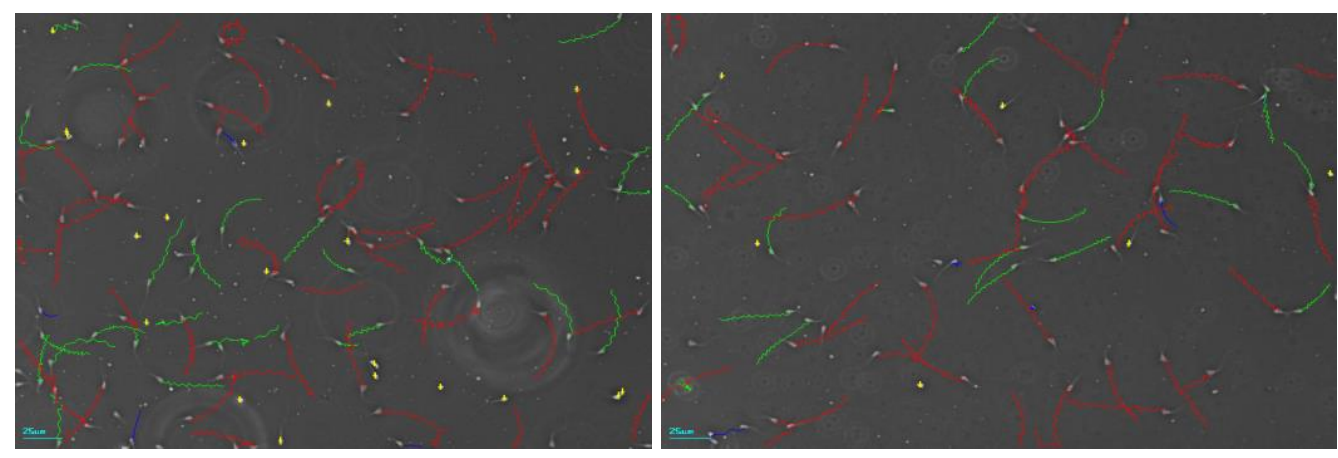

Figure 2. Sperms motility by using Leja (left) and MS (right) 
Table 2. Velocity spermatozoa of Ongole crossbred.

\begin{tabular}{lccc}
\hline \multirow{2}{*}{ Parameter } & \multicolumn{2}{c}{ Treatment } & \multirow{2}{*}{ Significance } \\
\cline { 2 - 3 } & Leja & Microscope Slide & \\
\hline $\operatorname{VCL}(\mu \mathrm{m} / \mathrm{s})$ & $39.0 \pm 5.9$ & $36.1 \pm 7.6$ & $0.389(\mathrm{P}>0.05)$ \\
$\operatorname{VSL}(\mu \mathrm{m} / \mathrm{s})$ & $20.8 \pm 4.4$ & $22.1 \pm 6.2$ & $0.200(\mathrm{P}>0.05)$ \\
$\operatorname{VAP}(\mu \mathrm{m} / \mathrm{s})$ & $27.3 \pm 4.4$ & $26.7 \pm 6.5$ & $0.116(\mathrm{P}>0.05)$ \\
\hline
\end{tabular}

Description: Different superscript on the same line shows significant differences $(\mathrm{P}<0.05)$.

There are 3 parameters velocity for the speed of movement of the spermatozoa including: VCL, VSL and VAP (Sarastina, Susilawati, Ciptadi; 2006). The results of observations of velocity spermatozoa during the research activities are listed in Table 2.

Based on Table 2, it is known that the parameters of the velocity spermatozoa between treatments did not show a significant difference. The velocity of spermatozoa movement on the curve path (VCL) showed the value of $39 \mu \mathrm{m} / \mathrm{s}$ (leja) and $36.1 \mu \mathrm{m} / \mathrm{s}$ (MS). The velocity of the spermatozoa in a straight or straight (VSL) path was $20.8 \mu \mathrm{m} / \mathrm{s}$ (leja) and $22.1 \mu \mathrm{m} / \mathrm{s}$ (MS). Meanwhile, the average movement velocity (VAP) was $27.3 \mu \mathrm{m} / \mathrm{s}$ (leja) and $26.7 \mu \mathrm{m} / \mathrm{s}(\mathrm{MS})$. These results are not in accordance with the results of the Contri et al. (2010) which stated that the use of ledja chamber has an effect on reducing spermatozoa velocity. VAP values approaching VSL indicate the swimming pattern of spermatozoa in straight paths with regular movement (Sarastina, Susilawati, Ciptadi; 2006).

The chamber type has no effect on spermatozoa velocity. In accordance with the statement of Perumal et al. (2014) that $\mathrm{pH}$, thickness, osmolarity and energy availability have an effect on velocity. There are three spermatozoa motility parameters that describe the spermatozoa swimming pattern, including: linearity (LIN), straightness (STR) and wobble (WOB). The values of these three parameters with different chamber type treatments during the research activities are listed in Table 3.

Table 3. LIN, STR and WOB spermatozoa of Ongole crossbred.

\begin{tabular}{lccc}
\hline \multirow{2}{*}{ Parameter } & \multicolumn{2}{c}{ Treatment } & \multirow{2}{*}{ Significance } \\
\cline { 2 - 3 } & Leja & Microscope Slide & \\
\hline LIN (\%) & $53.4 \pm 8.7$ & $60.8 \pm 8.1$ & $0.801(\mathrm{P}>0.05)$ \\
STR (\%) & $75.7 \pm 6.8$ & $82.3 \pm 7.6$ & $0.825(\mathrm{P}>0.05)$ \\
WOB (\%) & $70.2 \pm 6.7$ & $73.8 \pm 6.1$ & $0.717(\mathrm{P}>0.05)$ \\
\hline
\end{tabular}

Description: Different superscript on the same line shows significant differences $(\mathrm{P}<0.05)$.

Table 3 showed that there are no differences in the value of LIN, STR and WOB spermatozoa between treatments. The values of LIN, STR and WOB spermatozoa using leja are $53.4 \%$; $75.7 \%$ and $70.2 \%$. While the LIN, STR and WOB values of spermatozoa with microscope slide as chambers are $60.8 \% ; 82.3 \%$ and $73.8 \%$. These three parameters showed the spermatozoa swimming pattern. High value of LIN and STR values indicate a progressive spermatozoa swimming pattern. Low value of LIN values indicate that spermatozoa have hyperactivity. The other important parameter in motility spermatozoa assesment of bull are hyperactive spermatozoa. Table 4 shown hyperactive spermatozoa value by using ledja and microscope slide.

There was a significant difference in the value of spermatozoa hyperactivity by using Leja and microscope slide. Hyperactive values of spermatozoa using leja were higher $(\mathrm{P}<0.05)$ than using microscope slide, which was $7.3 \%$. Hyperactive spermatozoa showed the movement of spermatozoa which is very fast, but was not linear and tend to rotate 
(forming star grooves). Hyperactive spermatozoa are very possible to reach the egg and fertilize it (Susilawati, 2011). Hyperactive value of spermatozoa using leja was higher than using microscope slide. Leja and microscope slide have different depth and volume capacity. Volume capacity of ledja higher than microscope slide, so that spermatozoa can move freely and actively. Ratnawati (2017) stated that there are two opinions related to hyperactivity of spermatozoa. The first opinion stated that hyperactive spermatozoa showed spermatozoa with high energy availability so they actively moving.

The second opinion stated that the presence of hyperactive spermatozoa indicates spermatozoa capacitation / accumulation of $\mathrm{Ca} 2+$. Higher volume (20 $\mu 1)$ with more volume diluents indicates higher energy availability than microscope slides (3-4 $\mu \mathrm{l})$. There are several factors that influence the incidence of hyperactivity of spermatozoa, including: the origin of spermatozoa, individual variation, temperature and the presence of cumulus oophorus (Susilawati, 2011). Kraemer et al. (1998) stated that the field position analysis affects to the VCL, VSL and ALH values produced. The observation point at the top of the chamber produced lower VCL, VSL and ALH than the center of the chamber. In this study, the observation point (field) was carried out consistently in the center of the chamber / microscope slide, so that it did not produce conditions that were biased towards the VCL parameters.

This can be attributed to the tendency of higher hyperactive values if the VCL value is also high. However, it still has to consider the values of ALH and LIN parameters to be able to categorize hyperactive sperm. Previous studies stated that ALH and BCF motility parameters did not correlate with the fertility of bulls. However, these two parameters illustrate the pattern of spermatozoa head movements. The results of the observations during the research are shown in Table 5.

The ALH and BCF values of spermatozoa with leja and MS did not show significant differences. The ALH value indicates the width of the movement of the head of the spermatozoa to the side on the track. The high ALH value shows the movement of spermatozoa that tends to rotate and is an indication of hyperactivity of spermatozoa. Conversely, BCF is a good indication in the analysis of semen quality. This parameter describes the number of spermatozoa movements across the average pathway. The higher the BCF showed the progressive and regular sperm trajectory (not rotating) (Ratnawati, 2017).

Table 4. Hyperactivity spermatozoa of Ongole crossbred.

\begin{tabular}{lccc}
\hline \multirow{2}{*}{ Parameter } & \multicolumn{2}{c}{ Treatment } & \multirow{2}{*}{ Significance } \\
\cline { 2 - 3 } & Leja & Microscope Slide & \\
\hline Hiperactivity $(\%)$ & $7.3 \pm 2.8^{\mathrm{a}}$ & $2.8 \pm 1.7^{\mathrm{b}}$ & $0.049(\mathrm{P}<0.05)$ \\
\hline Description: Different superscript on the same line shows significant differences $(\mathrm{P}<0.05)$. &
\end{tabular}

Table 5. Value of ALH and BCF spermatozoa of Ongole crossbred.

\begin{tabular}{lccc}
\hline \multirow{2}{*}{ Parameter } & \multicolumn{2}{c}{ Treatment } & \multirow{2}{*}{ Significance } \\
\cline { 2 - 3 } & Leja & Microscope Slide & \\
\hline ALH $(\mu \mathrm{m})$ & $1.7 \pm 0.3$ & $1.4 \pm 0.2$ & $0.091(\mathrm{P}>0.05)$ \\
$\mathrm{BCF}(\mu \mathrm{m})$ & $9.6 \pm 1.4$ & $11.3 \pm 1.2$ & $0.669(\mathrm{P}>0.05)$ \\
\hline
\end{tabular}

Description: Different superscript on the same line showed significant differences $(\mathrm{P}<0.05)$.

\section{Economic Analysis}

Assessment results of the quality sperm motility with leja and microscope slide showed no difference. The use of microscope slides is more efficient than leja, because 1 package box (content of 50 slides) can be used to analyze 25 samples (duplo). Whereas, 1 package of ledja consist of 25 
slides and each slide can be used for analysis 25 samples (duplo) as well. The price range for each box of microscope slide is $\mathrm{Rp}$. 20,000 and 2,600,000 (leja). It can be stated that microscope slides which has a lower prices (efficiently), can be used in motility analysis by using CASA.

\section{CONCLUSION}

The use of a leja chamber and microscope slide did not affect the assessment result of sperm motility (motility, progressive motility, VCL, VSL, VAP, LIN, STR, WOB, ALH and BCF). Nevertheless, the use of leja chamber resulted a higher hyperactivity of spermatozoa than a microscope slide. It was recommended that microscope slide could support the assessment of motility and was more efficient.

\section{REFERENCES}

Arifiantini, R. I., Purwantara, B., \& Riyadhi, M. (2010). Occurrence of sperm abnormality of beef cattle at several artificial insemination centers in Indonesia. Animal Production, 12(1), 44-49.

Barth, A., \& Oko, R. (1989). Abnormal Morphology of Boine Spermatozzoa. USA: Iowa State University Press.

Broekhuijse, M. L. W. J., Šostarić, E., Feitsma, H., \& Gadella, B. M. (2011). Additional value of computer assisted semen analysis (CASA) compared to conventional motility assessments in pig artificial insemination. Theriogenology, 76(8), 1473-1486. https://doi.org/10.1016/j.theriogenolog y.2011.05.040

Chrenek, P., Makarevich, a V, Ostro, A., \& Bulla, J. (2008). Comparison of different evaluation chambers for analysis of rabbit spermatozoa motility parameters using casa system. Slovak Journal of Animal Science, 41(2), 60-66.

Contri, A., Valorz, C., Faustini, M., Wegher, L., \& Carluccio, A. (2010). Effect of semen preparation on casa motility results in cryopreserved bull spermatozoa. Theriogenology, 74(3), 424-435. https://doi.org/10.1016/j.the riogenology.2010.02.025

Gączarzewicz, D. (2015). Influence of chamber type integrated with computer-assisted semen analysis (CASA) system on the results of boar semen evaluation. Polish Journal of Veterinary Sciences, 18(4), 817-824. https://doi.org/10.1515/pjvs-2015-0106 Gloria, A., Carluccio, A., Contri, A., Wegher, L., Valorz, C., \& Robbe, D. (2013). The effect of the chamber on kinetic results in cryopreserved bull spermatozoa. Andrology, 1(6), 879885. https://doi.org/10.1111/j.2047-29 27.2013.00121.x

Kraemer, M., Fillion, C., Martin-Pont, B., \& Auger, J. (1998). Factors influencing human sperm kinematic measurements by the Celltrak computer-assisted sperm analysis system. Human Reproduction, 13(3), 611-619. https:// doi.org/10.1093/humrep/13.3.611

Krause, W. (1995). Computer-assisted semen analysis systems: comparison with routine evaluation and prognostic value in male fertility and assisted reproduction. Human Reproduction, 10(suppl 1), 60-66. https://doi.org/10. 1093/humrep/10.suppl_1.60

Lenz, R. W., Kjelland, M. E., VonderHaar, K., Swannack, T. M., \& Moreno, J. F. (2011). A comparison of bovine seminal quality assessments using different viewing chambers with a computerassisted semen analyzer1. Journal of Animal Science, 89(2), 383-388. https://doi.org/10.2527/jas.2010-3056

Perumal, P., Srivastava, S. K., Ghosh, S. K., \& Baruah, K. K. (2014). Computerassisted sperm analysis of freezable and nonfreezable mithun (bos frontalis) semen. Journal of Animals, 2014, 1-6. https://doi.org/10.1155/2014/675031

Ratnawati, D. (2017). Beberapa Parameter Motilitas Spermatozoa Semen Cair Pada Tiga Bangsa Sapi Lokal Dengan Tiga Pengencer Berbeda Selama Simpan Dingin. Universitas Brawijaya. 
Rurangwa, E., Kime, D., Ollevier, F., \& Nash, J. (2004). The measurement of sperm motility and factors affecting sperm quality in cultured fish. Aquaculture, 234(1-4), 1-28. https://doi. org/10.1016/j.aquaculture.2003.12.006

Sarastina, Susilawati, \& Ciptadi, G. (2006). Analysis of sperms motility in various of cattle breed by using computer assisted semen analysis (casa). Journal Cattle Tropical, 6(2), 1-12.
Susilawati, T. (2011). Spermatology (1st ed.). Malang: UB Press.

Vested, A., Ramlau-Hansen, C. H., Bonde, J. P., Thulstrup, A. M., Kristensen, S. L., \& Toft, G. (2011). A comparison of conventional and computer-assisted semen analysis (CRISMAS software) using samples from 166 young Danish men. Asian Journal of Andrology, 13(3), 453-458. https://doi.org/10.103 8/aja.2011.14 